\title{
Prevalence of the Metabolic Syndrome Among
} Batswana Adults in Urban and Semi-Urban Gaborone

\author{
Dawn Tladi $\mathbb{1}^{\prime}$ \\ Lucky Mokgatlhe 2 \\ Theo Nell (iD) ${ }^{3}$ \\ Sheila Shaibu ${ }^{4}$ \\ Ronel Mitchell ${ }^{5}$ \\ Comfort Mokgothu' \\ Tebogo Gabonthone' \\ Omphile Hubona' \\ 'Department of Sport Science, \\ University of Botswana, Gaborone, \\ Botswana; ${ }^{2}$ Department of Statistics, \\ University of Botswana, Gaborone, \\ Botswana; ${ }^{3}$ Centre for Cardio-metabolic \\ Research in Africa (CARMA), Integrated \\ Metabolic Research Group, Department \\ of Physiological Sciences, Faculty of \\ Natural Sciences, University of \\ Stellenbosch, Stellenbosch, 7600, South \\ Africa; ${ }^{4}$ School of Nursing and \\ Midwifery, The Aga Khan University, \\ Nairobi, Kenya; ${ }^{5}$ Gaborone Biokinetics, \\ Gaborone, Botswana
}

Correspondence: Dawn Tladi

Department of Sport Science, Private Bag 00702, Gaborone, Botswana

Tel +267 71896028

Fax +2673185096

Email tladidm@ub.ac.bw
Purpose: The metabolic syndrome (MetS) is on the rise in Sub-Saharan Africa, attributed to increased and uncontrollable urbanization accompanied by its lifestyle changes. Noncommunicable diseases, such as hypertension, diabetes, and obesity, which are components of the (MetS) are also on the increase in Botswana. To date, no study has determined the prevalence of the MetS in the apparently healthy Batswana adults. The objective of the study was to determine the prevalence of the MetS among the 25-65-year-old Batswana residing in urban and neighboring semi-urban areas of Gaborone.

Participants and Methods: A cross-sectional study was used to collect data from N=794 participants, $n=383$ men and $n=411$ women, residing in Gaborone and two surrounding semiurban areas. Data collected included demographic, anthropometric measurements, blood pressure (BP), blood glucose, triglycerides, high-density lipoprotein cholesterol (HDL-C) and total cholesterol.

Results: A high prevalence of $26.8 \%$ was reported, with women mostly afflicted $(35.0 \%$ vs $18.0 \%)$. The MetS risk factors found to be common in women were low HDL-C at $(50 \%$ vs $48.7 \%$ ) compared to men, while proportions with elevated BP (50.3\% vs $39.4 \%)$ were prominent in men. The prevalence increased with age, with the oldest age group showing a higher prevalence in both women and men, respectively (55-65 years; $38.5 \%$ vs $41.2 \%$ ).

Conclusion: An unprecedented high MetS prevalence was revealed among perceived to be healthy Batswana adults, with women at a higher risk. This public health concern creates an opportunity to establish evidence of risk factors, develop guidelines and strategies with appropriate public health measures to prevent and control the MetS.

Keywords: abdominal obesity, HDL-C, blood pressure, age, public health

\section{Introduction}

The Metabolic syndrome (MetS) is defined as a congregation of metabolic related disorders of abdominal obesity, raised fasting blood glucose (BG), glucose intolerance, elevated blood triglycerides (TG), low high-density lipoprotein cholesterol (HDL-C) and elevated blood pressure (BP). ${ }^{1-3}$ There has been a worldwide rapid increase in the MetS, and the Sub-Saharan African (SSA) nations have not been spared from the epidemic. ${ }^{4}$ Several hypotheses have been advanced to explain the explosion of the MetS, such as the increased and uncontrollable urbanization that is accompanied by lifestyle changes. Developing nations in particular, with a high and rapid urbanization will face a greater burden of non-communicable diseases (NCDs) in the very near future. 
Developing countries populations, minority groups and disadvantaged groups in general were established in the early 1990s as populations faced with the greatest risk of developing lifestyle diseases. ${ }^{5}$ According to the World Bank collection of development indicators, compiled from officially recognized sources, Botswana has an estimated diabetes prevalence of 5.8\% among 20-79 year olds, with the majority of the diabetic population being women in urban areas. ${ }^{6}$ This accentuates the fact that the disease burden, especially NCDs such as diabetes (type I and II), hypertension (HTN), and obesity are on the rise as well in the African continent. ${ }^{7-9}$

For several decades, the human immunodeficiency virus (HIV) pandemic has been the main focus for many SSA countries at the detriment of other equally deleterious diseases. The emergence and growth of these other equally adverse health conditions continued unimpeded in many SSA countries while all the focus was on the HIV pandemic. What further compounds the disease burden within this context is the close biochemical and clinical links between HIV positive patients and the MetS. Several studies have reported the existence of this link between anti-retroviral (ARV) treatment and the onset of MetS. $^{2,10,11}$ Furthermore, many HIV positive patients also present with MetS symptoms even before they start the ARV treatment. ${ }^{2}$ The prevalence of a combination of the two, HIV and the MetS may pose a double wormy for developing countries like Botswana who are still battling the unrelenting high prevalence of HIV.

While the most recent World Health Organization (WHO) step study of $2014^{12}$ reported increased NCDs such as HTN, diabetes, and obesity among Batswana adults, no study has documented the prevalence of these diseases congregating as a MetS in the apparently healthy population. For instance, Owolabi \& Keetile ${ }^{13}$ noted the high prevalence of overweight, obesity and HTN among urban Batswana men and women but not as a MetS. Having one component of the MetS does not diagnose one with the MetS, but it increases the risk of serious disease. Developing more components, as a MetS, further increases the risk of complications, such as cardiovascular disease (CVD) and diabetes. Cardiovascular risk factors increase the risk of CVD by 2 -fold and that of developing type 2 diabetes mellitus by 3-fold. ${ }^{14}$ Identifying people with the MetS has been shown to predict CVD morbidity, CVD mortality, type 2 diabetes and all-cause of mortality. ${ }^{15}$ The underlying biology, optimal diagnostic criteria, and clinical implications, once diagnosed, have been a matter of intense debate. Despite these areas of controversy, there is now a general consensus that the observed risk factor clustering signifies heightened cardiovascular risk. ${ }^{16}$ The MetS data provide useful and easily comprehensible information for the nation's public health system, culminating in the development of preventive strategies.

Garrido et $\mathrm{al}^{17}$ reported a high prevalence of the MetS and obesity among a small population of health care workers at the Kanye Adventist hospital in Botswana. Similarly, Omech et $\mathrm{al}^{18}$ also reported a high prevalence of the MetS in two Botswana general medical outpatient clinics of Princess Marina hospital and Letsholathebe II Memorial Hospital. These studies indicate the existence of the MetS risk factors independently ${ }^{13}$ and as a MetS, ${ }^{17,18}$ but only among health care workers at Kanye Hospital ${ }^{17}$ and outpatients at two general medical clinics. ${ }^{18}$ These specially selected populations left out the apparently healthy Batswana adults, whose MetS status has never been investigated. Leaving out an apparently healthy population can lead to underreporting of the actual prevalence of the MetS among Batswana adults.

Until the prevalence of the MetS in Botswana is accurately elucidated, the significance and the magnitude of the burden that it might bring to the health care system will not be realized. The MetS among Batswana adults needs to be thoroughly investigated, characterized and documented to inform public policy towards prevention and treatment options. Documentation will also guide the development and implementation of educational and physical activity interventions to fight the imminent MetS epidemic. Evidence of the prevalence and incidence of the MetS and related risk factors among the general apparently healthy population of Batswana adults is still lacking. Therefore, there is an urgent need to address the MetS, especially considering the tendency of a largely sedentary lifestyle among Batswana adults. ${ }^{12}$ The purpose of this study was to determine the prevalence of the MetS among the apparently healthy Batswana adults in Gaborone and neighboring semi-urban areas.

\section{Materials and Methods}

A cross-sectional study that employed a complex multi-stage cluster sampling method was used to recruit $n=1000$ participants in the city of Gaborone and neighboring semi-urban areas of Tlokweng and Mogoditshane. A complex sampling design entails a mixture of probability sampling methods. The study combined the stratification based on the three localities, with random selection of clusters in the form of malls which 
are nested within the localities. The malls were of two types, ranging from supermalls to small satellite malls, and respondents were nested within the malls, rendering the design a complex multi-stage sampling design (Figure 1). The target population was Botswana citizens, men and women aged 25 to 65 years residing in Gaborone, Tlokweng and Mogoditshane. Data were collected at shopping malls where people of heterogeneous characteristics converge. There were a total of 37 malls classified as a super mall or satellite mall, spread across Gaborone and the two areas. A total of seven malls were randomly selected for the study.

According to the World Bank collection of development indicators, ${ }^{6}$ Botswana has an estimated diabetes prevalence of $5.8 \%$ for the population aged 20-79 years. The prevalence of diabetes mellitus is believed to be on the increase in Botswana; hence, despite the $5.8 \%$ referenced, $8 \%$ was used as a reasonable estimate of the increase. Since the required sample size will increase with higher population prevalence, a prevalence of $8 \%$ amongst the 25-65 years cohort was assumed. The equation $n=\mathrm{Z}^{2}(1-\alpha / 2) \mathrm{P}(1-\mathrm{P}) / \delta^{2}$, where $\delta$ is the margin of error, $\mathrm{P}$, the prevalence level and $\mathrm{Z}$ the normal score corresponding to the (1- $\alpha) \%$ confidence level, with a 5\% type I error and assumed $8 \%$ diabetes prevalence in Botswana, was used to calculate the sample size at $n=452$.

Cognizance of the cluster sampling method being employed, the correlated responses were accounted for. The design effect was computed as $1+(\mathrm{m}-1) \rho$, where $\rho$ is the intraclass correlation and $\mathrm{m}$ is the cluster size. On average, there were 50 shops in the different malls in the sampling frame. Literature $^{19,20}$ has shown an intra-class correlation of $\rho=0.019$ for glucose measurements on a group of adults, giving an estimated design effect of between 1.5 and 2. For this study, the design effect was computed at 1.93 and approximated to 2. A design effect of 2 doubled the sample size to $n=904$. Furthermore, some critical questions on anthropometric measures may not be availed for some respondents due to refusal and/or non-response. Assuming a refusal rate of $10 \%$, the final sample size of $n=1000$ was targeted.

A sampling frame of all shopping malls in Gaborone and neighboring semi-urban areas of Tlokweng and Mogoditshane were compiled and a sample randomly selected from the list. In the selected malls, shoppers perceived to be eligible were systematically recruited as they passed-by the testing area. The recruitment was alternated between a stratifying variable, gender, to ensure a balance between men and women participants. Once eligibility had been established through use of the national identity card, and consent to participate had been sought, the participants were enrolled in the study.

Ethical approval was obtained from the Institutional Review Boards of both the University Of Botswana (round 24 Ref. no. UBR/RES 3/2) and Stellenbosch University (ref \#: IRB0005239), and from the Ministry of Health, Botswana (ref \# HRU 00806). Data were collected from volunteers who agreed to participate in the study after an introduction and briefing on the study intent. After informed consent was obtained, a total of $n=803$ volunteers were recruited, interviewed and assessed. Data regarding demographic, anthropometric and biochemical factors were collected. All procedures specified by the Health Professions Council of Botswana as good clinical practices were strictly adhered to.

Demographic data included questions related to gender, age, level of education, marital and work status, number of people above 18 years in the household and average yearly earnings. Medical history included questions related to the history of elevated BP, diabetes, TC and CVD. Resting BP, height and weight, waist and hip circumferences were measured. Biochemical measures gathered data related to BG and blood lipids (TC, TG and HDL-C). Blood pressure measurements were taken using an automated BP monitor
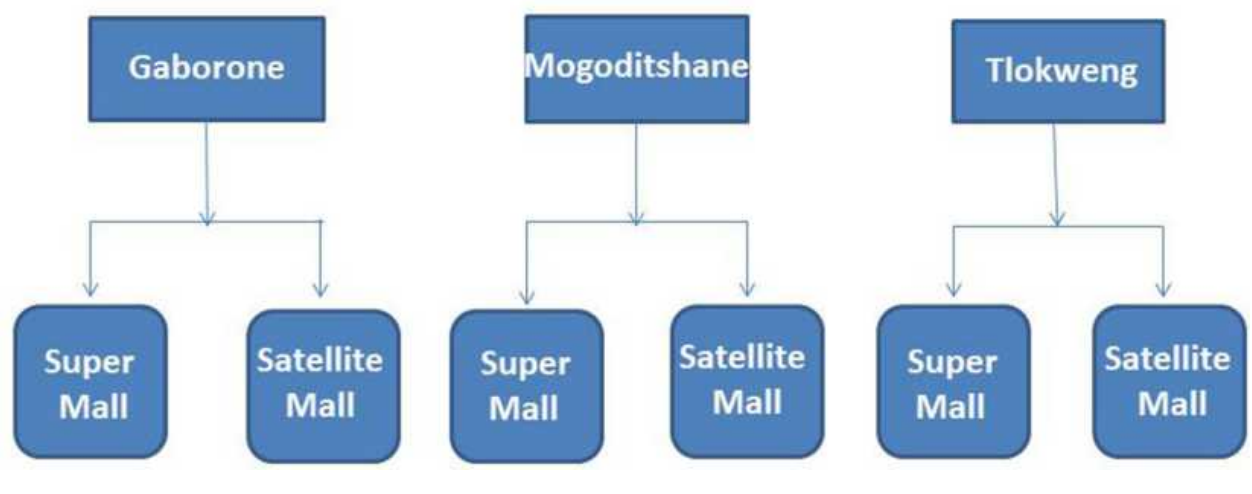

Figure I Complex multi-stage cluster sampling method schematic diagram. 
(OMRON Intelli Sense M3W) after a five-minute rest while seated, following the interview. Two BP measures were taken and the average recorded. When the BP was found to be more than $120 / 80 \mathrm{mmHg}$, the participant was allowed more rest and the BP measure was repeated and the final reading recorded.

Waist and hip circumferences were measured using a SECA Measuring tape $(201 \mathrm{~cm})$ according to the International Society for the Advancement of Kinanthropometry (ISAK) standard guidelines. ${ }^{21}$ Height was measured with a portable SECA stadiometer using the free-standing method with the head placed in the Frankfort plane and weight was measured with the SECA Alpha Digital scale (Model 770). Random nonfasted capillary BG, TG, and TC were assessed via a finger prick test with the Care Sense N BG monitoring system, while the blood lipids were measured using the Cardio Check PA system.

There are mainly three broad definitions of the MetS, ${ }^{22-24}$ however the definition most relevant to the African setting has been established to be that of the International Diabetes Federation (IDF). ${ }^{24}$ To be categorized as having the MetS the IDF criterion was used. Thus, the presence of central obesity (defined as waist circumference $\geq 94 \mathrm{~cm}$ for European men, and $\geq 80 \mathrm{~cm}$ for women, with ethnic specific values for other groups) plus any two of the following four factors; raised $\mathrm{TG} \geq 3.9$ mmol/L, low HDL-C $($ men $<1.0 \mathrm{mmol} / \mathrm{L}$; women $<1.3$ $\mathrm{mmol} / \mathrm{L}$ ) or on dyslipidemia medication, elevated $\mathrm{BG} \geq$ $5.6 \mathrm{mmol} / \mathrm{L}$ (or elevated non-fasting $\mathrm{BG}$ of $11.1 \mathrm{mmol} / \mathrm{L}$ as was the case in the current study) or on diabetes medication or elevated $\mathrm{BP} \geq 130 / 85 \mathrm{mmHg}$ or on HTN medication. ${ }^{24}$

Statistical analysis was conducted using Statistical Package for Social Sciences (SPSS version 22). Most of the variables analyzed for this output were quantitative; hence, their means \pm standard deviations were reported. All variables tested were contrasted by gender using the Student's t-tests. Contrasts for proportions among subpopulations were performed using homogeneity chisquare tests. A significant difference was accepted if p-values were less than 0.05 for both tests.

\section{Results}

A total of $n=800$ respondents participated in the study drawn from seven shopping malls, yielding an $80 \%$ response rate. From the $n=800$ participants, $n=664$ were selected from malls in Gaborone and the remaining $n=136$ from Tlokweng and Mogoditshane. The results are based on the participants ( $n=383$ men and $n=411$ women) who had complete data for relevant variables. No significant difference between ages was reported between genders (Table 1). Additionally, the sample did not yield any gender-based differences for waist circumference, diastolic BP, BG and TG. However, a significant gender effect was observed in BMI $(p<0.001)$, hip circumference $(p<0.001)$,

Table I Participants Anthropometrics, Blood Pressure and Biochemical Measures by Gender

\begin{tabular}{|c|c|c|c|c|c|}
\hline Characteristic & $\mathbf{n}$ & All & Men & Women & P-value \\
\hline n (\%) & 800 & & $384(48)$ & $416(52)$ & \\
\hline Age (years) & 743 & $36.1 \pm 8.9$ & $36.3 \pm 9.2$ & $35.9 \pm 8.6$ & 0.583 \\
\hline BMI $\left(\mathrm{kg} / \mathrm{m}^{2}\right)$ & 797 & $26.2 \pm 5.7$ & $24.2 \pm 4.5$ & $27.9 \pm 6.1$ & $<0.001$ \\
\hline Waist $(\mathrm{cm})$ & 794 & $85.1 \pm 13.9$ & $84.1 \pm 13.3$ & $86.0 \pm 14.4$ & 0.05 \\
\hline $\mathrm{Hip}(\mathrm{cm})$ & 795 & $104.2 \pm 12.8$ & $99.6 \pm 10.5$ & $108.5 \pm 13.3$ & $<0.001$ \\
\hline Waist Hip Ratio & 794 & $0.82 \pm 0.1$ & $0.85 \pm 0.11$ & $0.79 \pm 0.11$ & $<0.001$ \\
\hline Systolic blood pressure $(\mathrm{mmHg})$ & 795 & $127.5 \pm 16.9$ & $130.4 \pm 16.7$ & $124.7 \pm 16.6$ & $<0.001$ \\
\hline Diastolic blood pressure $(\mathrm{mmHg})$ & 795 & $78.8 \pm 10.8$ & $79.2 \pm 11.0$ & $78.5 \pm 10.7$ & 0.378 \\
\hline Blood glucose (mmol/L) & 779 & $5.3 \pm 1.3$ & $5.3 \pm 1.2$ & $5.4 \pm 1.5$ & 0.201 \\
\hline Total triglycerides $(\mathrm{mmol} / \mathrm{L})$ & 785 & $1.9 \pm 2.4$ & $1.8 \pm 1.0$ & $2.0 \pm 1.1$ & 0.057 \\
\hline HDL cholesterol $(\mathrm{mmol} / \mathrm{L})$ & 778 & $1.2 \pm 0.4$ & I.I \pm 0.4 & $1.3 \pm 0.4$ & $<0.001$ \\
\hline
\end{tabular}


waist-hip ratio $(\mathrm{p}<0.001)$, systolic $\mathrm{BP}(\mathrm{p}<0.001)$ and HDL$\mathrm{C}(\mathrm{p}<0.001)$. The women presented with a higher BMI $\left(27.9 \mathrm{~kg} / \mathrm{m}^{2}\right.$ vs $\left.24.2 \mathrm{~kg} / \mathrm{m}^{2}\right)$, waist circumference $(86.0 \mathrm{~cm}$ vs $84.1 \mathrm{~cm})$ and HDL-C $(1.3 \mathrm{mmol} / \mathrm{L}$ vs $1.1 \mathrm{mmol} / \mathrm{L})$, while the men had higher systolic BP (130.4 mmHg vs $124.7 \mathrm{mmHg}$ ) (Tables 1 and 2).

\section{Prevalence of the Metabolic Syndrome}

The overall prevalence of the MetS was estimated at $26.8 \%$. The prevalence was found to be higher among the women at $35.0 \%$ vs men $18.0 \%$ (Table 2). Overall, low HDL-C identified the highest candidates for MetS at $49.4 \%$, followed by $\mathrm{TG}$ at $47.4 \%$ and elevated BP at $44.7 \%$ (Table 2).

The oldest age-group (55-65 years) showed the highest prevalence of the MetS, for men presenting at $41.2 \%$ compared to women at $38.5 \%$ (Table 3). The MetS prevalence increased with age, from 10.4\%: $25-34$ age group, 20.4\%: 35-44 age group, 33.3\%: 45-54 age group and 41.2\%: 55-65 age group among men. A similar trend was observed in the women with the MetS prevalence increasing from 27.9\%: 25-34 age group, 38.6\%: 35-44 age group, 50.0\%: 45-54 age group and 55-64 age group, $38.5 \%$. Overall, women presented a higher prevalence than men in all age groups except in the older age group of 55-64 years (Table 3).

Table 2 Percentage Prevalence of the Metabolic Syndrome Components

\begin{tabular}{|c|c|c|c|c|c|}
\hline \multirow[t]{2}{*}{ Component } & \multirow[t]{2}{*}{$\mathbf{n}$} & \multicolumn{3}{|c|}{$\begin{array}{c}\text { Component Prevalence } \\
\text { (\%) }\end{array}$} & \multirow[t]{2}{*}{ Pvalue } \\
\hline & & All & Men & Female & \\
\hline \multicolumn{6}{|l|}{ BMI $\left(\mathrm{kg} / \mathrm{m}^{2}\right) \%$} \\
\hline $25 \leq \mathrm{BMI}<30$ & 232 & 29.1 & 15.1 & 31.0 & $<0.001$ \\
\hline $\mathrm{BMI} \geq 30^{*}$ & 192 & 24.1 & 13.0 & 34.4 & $<0.001$ \\
\hline \multicolumn{6}{|l|}{ Waist $(\mathrm{cm})$ (men/women) } \\
\hline$\geq 94 / 80$ & 380 & 47.9 & 24.5 & 69.6 & $<0.001$ \\
\hline$\geq 102 / 88^{*}$ & 230 & 29.0 & 11.0 & 45.7 & $<0.001$ \\
\hline WHR $>1.0 / 0.85$ & 106 & 13.4 & 3.7 & 22.6 & $<0.001$ \\
\hline Elevated BP $(\geq|30| \geq 85) *$ & 355 & 44.7 & 50.3 & 39.4 & 0.002 \\
\hline Blood Glucose $\geq 11.1 \mathrm{mmol} / \mathrm{L}^{*}$ & 6 & 0.8 & 0.5 & 1.0 & 0.408 \\
\hline $\mathrm{TG} \geq 1.7 \mathrm{mmol} / \mathrm{L}(\%)^{*}$ & 372 & 47.4 & 46.3 & 48.4 & 0.555 \\
\hline $\mathrm{HDL}<1.03 / 1.29 \mathrm{mmol} / \mathrm{L} *$ & 384 & 49.4 & 48.7 & 50.0 & 0.711 \\
\hline Metabolic Syndrome & 794 & 26.8 & 18.0 & 35.0 & $<0.001$ \\
\hline
\end{tabular}

Notes: *Cut off values.
To assess the prevalence of individual components of the MetS, comparative levels of component-risk among those classified with and without the MetS were computed. Other than waist circumference, which is a requirement for diagnosing the MetS, among men with METS, elevated TG was the most prevalent risk factor (87\%) followed by elevated BP (81\%). The likelihood for increased TG amongst men with Mets increased by $46 \%$ when compared to men without Mets, relative risk=1.46 $(1.30,1.63)$, while risk for elevated BP increased by $32 \%$ amongst men with MetS compared to those without. The women with the MetS showed a 79\% prevalence of low HDL-C, followed by elevated TG at $75 \%$. The risk for HDL-C amongst women with MetS almost doubled with relative risk=1.95 $(1.65,2.31)$, when compared to women without MetS. The likelihood of having a high TG among women with MetS increased by $85 \%$ when compared to those without the MetS. Interesting to note is that even though the prevalence of elevated BP among women is not as high at $72 \%(64.5-79.0)$ when compared to the men, the relative risk for BP is $2.37(1.91,2.94)$ (Table 4).

\section{Discussion}

The main objective of the study was to determine the prevalence of the MetS among the apparently healthy Batswana adults in Gaborone and the neighbouring semiurban areas of Tlokweng and Mogoditshane. The findings revealed a high overall prevalence of $26.8 \%$ among those sampled. Garrido, Semeraro, Temesgen, and Simi ${ }^{17}$ assessed the MetS prevalence among a small special group of Batswana health care workers at Kanye Seventhday Adventist Hospital and reported a prevalence of $34.0 \%$. Omech et $\mathrm{al}^{18}$ recently reported a prevalence of $27.1 \%$ among an outpatient population from two general medical outpatient clinics in Botswana. However, these studies applied the ATP III criterion ${ }^{23}$ to determine the presence of the MetS. The prevalence reported by Omech et $\mathrm{al}^{18}$ was found to be similar to the current study at $26.8 \%$. These results do confirm a MetS prevalence of $\sim 30 \%$ among Batswana adults, in different population groups, indicating an emerging country-wide health problem.

Erasmus et $\mathrm{al}^{25}$ and Peer et $\mathrm{al}^{26}$ reported an even higher prevalence in urban South African populations. Erasmus et $\mathrm{al}^{25}$ reported a very high crude prevalence of $60.6 \%$ (using IDF criterion) among mixed ancestry of Cape Town, South Africa, while Peer et $\mathrm{al}^{26}$ reported a high ageadjusted prevalence of $31.7 \%$ among Black people in the 
Table 3 Age and Sex-Specific Percentage Prevalence of the Metabolic Syndrome

\begin{tabular}{|c|c|c|c|c|c|c|}
\hline \multirow[t]{2}{*}{ Age Groups (Years) } & \multicolumn{2}{|c|}{ All $(n=794)$} & \multicolumn{2}{|c|}{ Men $(n=383)$} & \multicolumn{2}{|c|}{ Women $(n=4 I I)$} \\
\hline & $\mathbf{n}$ & $\%(95 \% \mathrm{Cl})$ & $\mathbf{n}$ & $\%(95 \% \mathrm{Cl})$ & $\mathbf{n}$ & $\%(95 \% \mathrm{Cl})$ \\
\hline $25-34$ & 391 & $19.7(16.0,23.8)$ & 183 & $10.4(6.5,15.3)$ & 208 & $27.9(21.8,33.8)$ \\
\hline $35-44$ & 212 & $30.2(24.3,36.6)$ & 98 & $20.4(I 3.4,29.2)$ & 114 & $38.6(30.0,47.7)$ \\
\hline $45-54$ & 106 & $42.5(33.4,52.0)$ & 48 & $33.3(21.3,47.3)$ & 58 & $50.0(37.4,62.6)$ \\
\hline $55-65$ & 30 & $40.0(24.0,57.8)$ & 17 & $41.2(20.7,64.4)$ & 13 & $38.5(16.5,65.0)$ \\
\hline Not stated & 55 & $27.3(16.9,40.0)$ & 37 & $18.9(8.9,33.6)$ & 18 & $44.4(2||,. 6 \mid .6)$ \\
\hline Mets prevalence & 794 & $26.8(23.8,30.0)$ & 383 & I8.0 $(\mid 4.4,22.0)$ & 411 & $35.0(30.2,39.3)$ \\
\hline Age adjusted & - & 28.9 & - & 20.4 & - & 36.1 \\
\hline
\end{tabular}

same population. The prevalence of the MetS in SSA has been reported to vary between $0 \%$ and $50 \%$, and even higher for some countries, ${ }^{7}$ placing Botswana among the highly afflicted countries in the region at $26.8 \%$.

At gender level, the prevalence of the MetS was found to be higher among women (35.0\%) compared to men $(18.0 \%)$, in congruent with most studies that investigated the prevalence of the MetS in $\mathrm{SSA}^{25-30}$ as well as among African-Americans. ${ }^{31}$ Peer et al $^{26}$ attributed this gender difference in SSA and African-Americans to be perhaps related to cultural values and positive social attitudes towards obesity. Traditionally, being overweight among these cultures is generally associated with good health and attractiveness in women ${ }^{26}$ which is the case even in
Botswana. ${ }^{17,32}$ Furthermore, due to the HIV and AIDS epidemic in Botswana, adiposity is associated with being HIV and AIDS negative and most women would prefer to be overweight. Other local factors too such as eating habits, sedentary behaviours, and work, lifestyle habits forced onto women by cultural expectations could have contributed to the higher prevalence of the MetS in the women. The high prevalence of the MetS and obesity among women, though, is of great concern and needs gender-specific interventions urgently in a culturally sensitive context.

The oldest age group (55-65 years) was found to be more afflicted, with the highest prevalence of 39\% among women and $41 \%$ in the men. The increase in the MetS

Table 4 Component-Wise Prevalence and Relative Risk Among Participants with and without the Metabolic Syndrome

\begin{tabular}{|c|c|c|c|c|c|c|}
\hline \multirow{3}{*}{$\begin{array}{l}\text { Component } \\
\text { All }(n=794)\end{array}$} & \multirow[t]{3}{*}{ Total } & \multicolumn{4}{|c|}{ MetS Status } & \multirow[t]{3}{*}{ Relative Risk $(95 \% \mathrm{Cl})$} \\
\hline & & \multicolumn{2}{|c|}{ Absent } & \multicolumn{2}{|c|}{ Present } & \\
\hline & & $\%$ & $95 \% \mathrm{Cl}$ & $\%$ & $95 \% \mathrm{Cl}$ & \\
\hline Central Obesity (\%) & 380 & 28.7 & $25.2-32.5$ & 100.0 & - & - \\
\hline High Triglycerides (\%) & 369 & 35.4 & $31.5-39.4$ & 79.1 & $73.3-84.2$ & $1.63(1.48-1.80)$ \\
\hline Low HDL cholesterol (\%) & 382 & 38.0 & $34.1-42.1$ & 79.2 & $73.4-84.3$ & $1.58(1.44-1.74)$ \\
\hline Elevated BP (\%) & 348 & 33.3 & $29.6-37.2$ & 75.1 & $69.0-80.6$ & $1.61(1.45-1.78)$ \\
\hline High Blood glucose & 6 & 0.0 & - & 2.9 & $1.2-5.8$ & - \\
\hline \multicolumn{7}{|l|}{ Male $(n=383)$} \\
\hline Central Obesity (\%) & 94 & 8.0 & $5.3-11.3$ & 100.0 & - & - \\
\hline High Triglycerides (\%) & 174 & 37.0 & $31.8-42.5$ & 87.0 & 77.5-93.3 & $1.46(1.30-1.63)$ \\
\hline Low HDL cholesterol (\%) & 182 & 41.5 & $35.1-45.9$ & 79.7 & $69.1-87.9$ & $1.33(1.20-1.47)$ \\
\hline Elevated BP (\%) & 192 & 43.3 & $37.9-48.8$ & 81.2 & $70.8-89.0$ & $1.32(1.19-1.45)$ \\
\hline High Blood glucose (\%) & 2 & 0.0 & - & 3.0 & $0.6-9.4$ & - \\
\hline \multicolumn{7}{|l|}{ Female $(n=4 I I)$} \\
\hline Central Obesity (\%) & 286 & 53.2 & $47.2-59.1$ & 100.0 & - & - \\
\hline High Triglycerides (\%) & 195 & 33.5 & $28.0-39.3$ & 75.4 & $67.8-81.9$ & $1.85(1.56-2.18)$ \\
\hline Low HDL cholesterol (\%) & 200 & 33.9 & $28.3-39.8$ & 79.0 & $71.8-85.1$ & $1.95(1.65,2.31)$ \\
\hline Elevated BP (\%) & 161 & 21.5 & $16.9-26.7$ & 72.2 & $64.5-79.0$ & $2.37(1.91-2.94)$ \\
\hline High Blood glucose (\%) & 4 & 0.0 & - & 2.4 & $0.9-6.5$ & - \\
\hline
\end{tabular}


prevalence with age is widely reported by other studies in $\mathrm{SSA}^{7,9,25}$ and elsewhere. ${ }^{31,33-35}$ Like in other similar studies investigating women, the MetS escalate to very high proportions in the 55-65 age group, of which some have attributed to the changes that occur with the onset of menopause. ${ }^{36-39}$

Menopause, indeed, has been reported to be an independent predictor of MetS in women. ${ }^{38}$ Unfavorable cardiovascular risk factor levels are observed during menopause, including changes in body fat distribution from a gynoid to an android pattern, abnormal blood lipid levels, increased sympathetic tone, endothelial dysfunction, vascular inflammation, and increased BP. ${ }^{39}$ Estrogen deficiency has been associated with the onset of these unfavorable cardiovascular risk factors. ${ }^{40}$ If estrogens and estrogen receptors regulate various aspects of glucose and lipid metabolism, disturbances of this metabolic signal could lead to the development of the MetS and a higher cardiovascular risk in women. ${ }^{41}$ Estrogen is believed to confer protection against the MetS in pre-menopausal women, even though the protective nature or mechanisms involved have not yet been fully elucidated. What is clear is that with a decline in estrogen at menopause, all these mechanisms that estrogen is said to regulate fail and result in the emergence of the MetS risk factors.

The disturbances to the various aspects of glucose and lipid metabolism due to hormonal changes with age have also been observed in men. There is strong evidence that a low testosterone level and clinical hypogonadism have a high prevalence in men with the MetS and/or type 2 diabetes. ${ }^{42}$ Many components of the MetS are adversely affected, especially in relation to cardiovascular risk in the presence of hypogonadism. Testosterone deficiency, which occurs with aging in men, is a risk factor in itself for the subsequent development of the the MetS and type 2 diabetes. ${ }^{42,43}$

Deficiency of sex hormones that occur with aging in both men and women plays a big role in the emergence of the MetS in old age. The prevalence of the MetS among women in the current study, which is very high even for the younger age groups of 25-34 years (28\%) and 35-44 years $(39 \%)$, is of great concern. Therefore, screening for CVDs should begin at the onset of menopause and should also be available to younger women and men in order to prevent the onset of the MetS in the general population.

The two MetS risk factors, accompanying central obesity, that were found to be the most prevalent among all

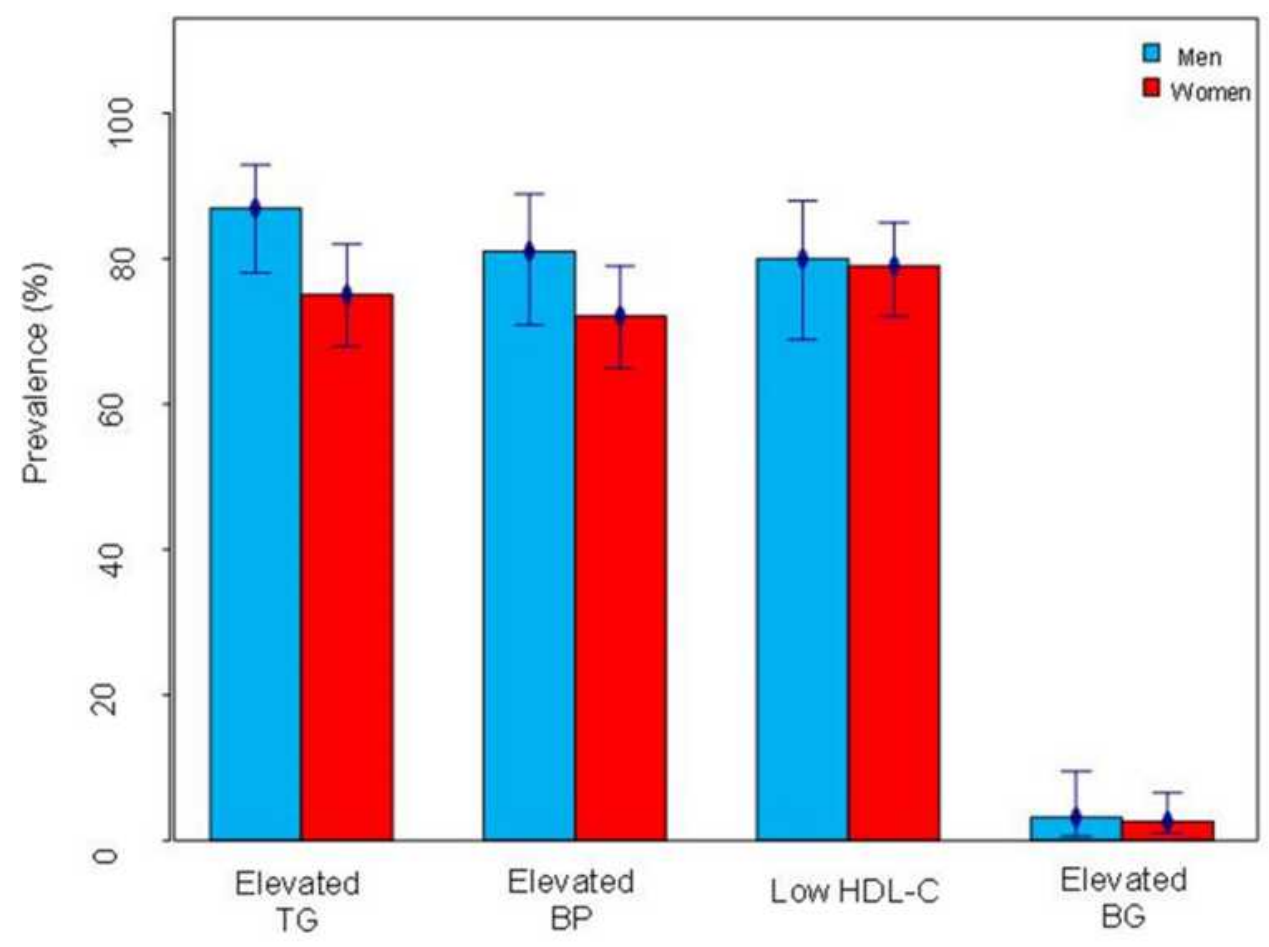

Metabolic syndrome components

Figure 2 Percentage prevalence of the metabolic syndrome components by gender. 
women were low HDL-C and high TG (Table 2). Among the women with the MetS, the most prevalent risk factors were still found to be low HDL-C and high TG (Figure 2). The most prevalent risk factors accompanying central obesity in all men was elevated BP, followed by low HDL-C (Table 1). Among the men with the MetS, the risk factors accompanying central obesity were found to be elevated TG, followed by BP (Figure 2). The present results reveal high TG as an emerging high MetS risk factor predominant in both men and women who have the MetS.

The results are similar to those of Erasmus et $\mathrm{al}^{25}$ who reported a prevalence of $75.0 \%$ low HDL-C in women and $51.4 \%$ elevated BP in men residing in the predominantly black townships of Cape Town, South Africa. Delineating the most prevalent risk factors helps guide interventional programs geared towards reducing the MetS, as the risk factors can be isolated and treated individually. Overall, the three most common risk factors were central obesity, elevated BP and dyslipidemia (low HDL-C and high TG), suggesting a high risk for CVDs in the population investigated. The results are not surprising since increased obesity has been reported to increase circulating free fatty acids concentrations, thus increasing plasma TG. ${ }^{3}$

To successfully prevent or treat the MetS, lifestyle modification and pharmacological interventions have to be employed. Pharmacologically, medications exist for the treatment of all MetS risk factors but due to the clustering of these components, the individual has to take several types of medication. The increased medication burden might lead to increased cost and contribute to poor adherence. This leaves lifestyle modification as the most viable intervention to be pursued, through community-based educational programs aiming toward behavioural change and ultimately increasing physical activity. Regular physical activity has been found to successfully mitigate all MetS risk factors. ${ }^{44,45}$ A life course prevention approach for both men and women should be encouraged as it has been shown to mitigate NCDs later in life. ${ }^{46}$

The current study presented some limitations, for instance, targeting malls might have left out a portion of the population that does not frequent malls. One time measures of biochemical parameters could be a limitation, but this method has been found to provide a good screening tool for the CVDs risk factors. Fasting prior blood sampling was not controlled for; therefore, the results were based on random non-fasted blood samples. However, the present study was able to reach the apparently healthy population whose MetS status has never been investigated.

\section{Conclusion}

The present study revealed a high prevalence of the MetS among Batswana women in an age-dependent modus. There is also an unacceptably high prevalence in the younger group of Batswana participants. The most prevalent components have been identified as central obesity and low HDL-C in women and elevated BP among men. The prevalence of dyslipidemia needs close attention, especially that it is not routinely checked during regular hospital visits as in the case of BP, but seems to be common in apparently healthy populations. If risk factors leading to MetS are not identified and sustainable measures put into place, this could lead to far-reaching public health consequences. Therefore, there is a need to establish evidence of risk factors among the general population at large. There is a need to develop guidelines, lay strategic plans and appropriate public health measures to prevent and control the MetS.

It is recommended that a national policy be developed to address the risk factors through an integrated approach. There should be increased promotion of healthy lifestyles and all health programs should include a preventive element. The programs should drive all the focus towards risk reduction, fighting obesity, developing health promotion legislation, promoting regular physical exercise and ultimately providing periodic basic screening tests. The investigation into the MetS prevalence could be extended to other parts of the country and rural areas which could also be harbouring high prevalence rates. An investigation should also be carried out to determine the role of urbanization and the nutrition transition play in this epidemic.

\section{Abbreviations}

MetS, metabolic syndrome; BP, blood pressure; HDL-C, high density lipoprotein cholesterol; IDF, International Diabetes Federation; BG, blood glucose; TG, triglycerides; TC, total cholesterol; SSA, Sub-Saharan Africa; NCDs, noncommunicable diseases; HTN, hypertension; CVD, cardiovascular disease; HIV/AIDS, human immunodeficiency virus/ acquired immunodeficiency syndrome; WHO, World health Organisation; UN, United Nations; ISAK, International Society for the Advancement of Kinanthropometry; ATP III, National Cholesterol Education Program Expert Panel on Detection, Evaluation, And Treatment of High Blood Cholesterol in Adults (Adult Treatment Panel III). 


\section{Data Sharing Statement}

The datasets used and/or analyzed during the current study are available from the corresponding authors on reasonable request.

\section{Ethics Approval and Consent to Participate}

Ethical approval was obtained from the University of Botswana, Office of Research Development and from the Human Research Office of the Ministry of Health, Botswana (ref \# HRU 00806). Informed consent was also obtained from the participants after introduction and briefing regarding the intent of the study.

\section{Authorship}

All authors made a significant contribution to the work reported, that is in the conception, study design, execution, acquisition of data, analysis and interpretation; took part in drafting, revising or critically reviewing the article; gave final approval of the version to be published; have agreed on the journal to which the article has been submitted; and agree to be accountable for all aspects of the work.

\section{Acknowledgments}

This work was supported by a grant from the Office of Research and Development of the University of Botswana grant (round 24 Ref. no. UBR/RES 3/2) and the Stellenbosch University's African Collaboration grant (ref \#: IRB0005239). Opinions, findings and conclusions or recommendations expressed in this study are those of the authors, the above-mentioned funding sources do not accept any liability in regard thereto. The authors would like to acknowledge the participants and research assistants for their contribution toward the success of this study. The mall owners are also acknowledged for allowing data collection on their premises.

\section{Disclosure}

The authors report no conflicts of interest in this work.

\section{References}

1. Cornier MA, Dabelea D, Hernandez TL, et al. The metabolic syndrome. Endocr Rev. 2008;29:777-822.

2. Young F, Critchley JA, Johnstone LK, Unwin NC. A review of co-morbidity between infectious and chronic disease in Sub-Saharan Africa: TB and diabetes mellitus, HIV and metabolic syndrome and the impact of globalization. Glob Health. 2009;5:1-9. doi:10.1186/17448603-5-9
3. O'Neill S, O'Driscoll L. Metabolic syndrome: a closer look at the growing epidemic and its associated pathologies. Obes Rev. 2015;16 (1):1-12. doi:10.1111/obr.12229

4. Mbanya J-C, Motala AA, Sobngwi E, Assah FK, Enoru ST. Diabetes in sub-Saharan Africa. Lancet. 2010;375:2254-2266. doi:10.1016/ S0140-6736(10)60550-8

5. Ntandou G, Delisle H, Agueh V, Fayomi B. Abdominal obesity explains the positive rural-urban gradient in the prevalence of the metabolic syndrome in Benin, West Africa. Nutr Res. 2009;29 (3):180-189. doi:10.1016/j.nutres.2009.02.001

6. The World Bank data. International diabetes federation, dieabetes atlas. Available from: https://data.worldbank.org/indicator/SH.STA. DIAB.ZS?locations=BW. Accessed May 11, 2021.

7. Fezeu L, Balkau BK, Kengne A-P, Sobngwi E, Mbanya,J-C. Metabolic syndrome in a sub-Saharan African setting: central obesity may be the key determinant. Atherosclerosis. 2007;193(1):70-76. doi:10.1016/j.atherosclerosis.2006.08.037

8. Vorster HH. The emergence of cardiovascular disease during urbanization of Africa. Public Health Nutr. 2002;5:239-243. doi:10.1079/ PHN2001299

9. Okafor C. The metabolic syndrome in Africa: current trends. Indian $J$ Endocrinol Metab; . 2012;16(1):56-66. doi:10.4103/2230-8210.91191

10. Haubrich RH, Riddler SA, DiRienzo AG, et al. AIDS Clinical Trials Group (ACTG) A5142 Study Team. Metabolic outcomes in a randomized trial of nucleoside, nonnucleoside and protease inhibitor-sparing regimens for initial HIV treatment. AIDS. 2009;23 (9):1109-1118. doi:10.1097/QAD.0b013e32832b4377

11. Villarroya F, Domingo P, Giralt M. Drug-induced lipotoxicity: lipodystrophy associated with HIV-1 infection and antiretroviral treatment. Biochim Biophys Acta. 2010;1801(3):392-399. doi:10.1016/j.bbalip.2009.09.018

12. Ministry of Health Botswana and World Health Organization. Botswana STEPS Non Communicable Disease Risk Factors Survey 2014 STEP Survey. Geneva: World Health Organization; 2015. Available from: https://www.who.int/ncds/surveillance/steps/STEPS BOTSWANA_2014_Report_Final.pdf?ua=1. Accessed May 11, 2021.

13. Owolabi EO, Keetile L. Overweight, Obesity and Metabolic Syndrome in Botswana. Paper Presented the 8th International Institute of Health Promotion Biennial Congress. Germany: Institute for Sports and Sport Science of the University of Heidelberg; 2007.

14. Reaven G. Metabolic syndrome: pathophysiology and implications for management of cardiovascular disease. Circulation. 2002;106 (3):286-288. doi:10.1161/01.cir.0000019884.36724.d9

15. Ford ES. Risks for all-cause mortality, cardiovascular disease, and diabetes associated with the metabolic syndrome: a summary of the evidence. Diabetes Care. 2005;28:1769-1778. doi:10.2337/diacare.28.7.1769

16. Pradhan AD. Sex differences in the metabolic syndrome: implications for cardiovascular health in women. Clin Chem. 2014;60 (1):44-52. doi:10.1373/clinchem.2013.202549

17. Garrido RA, Semeraro MB, Temesgen SM, Simi MR. Metabolic syndrome and obesity among workers at Kanye Seventh day Adventists Hospital, Botswana. SAMJ. 2009;99(5):331-334.

18. Omech B, Tshikuka J, Mwita JC, Tsima B, Nkomazana O, AmoneP'Olak K. Prevalence and determinants of metabolic syndrome: a cross-sectional survey of general medical outpatient clinics using national cholesterol expanded program-adult treatment panel III criteria in Botswana. Diabetes Metab Syndr Obes. 2016;9:273-279. doi:10.2147/DMSO.S109007

19. Mehata S, Shrestha N, Mehta RK, et al. Prevalence of the metabolic syndrome and its determinants among Nepalese adults: findings from a nationally representative cross-sectional study. Sci Rep. 2018;8 (14995). doi:10.1038/s41598-018-33177-5

20. Wong-McClure RA, Gregg EW, Barceló A, et al. Prevalence of metabolic syndrome in Central America: a cross-sectional population-based study. Rev Panam Salud Publica. 2015;38 (3):202-208. 
21. Syewart A, Marfell-Jones M, Olds T, de Ridder H International standards for anthropometric assessment ISAK manual. 2011 ISBN 0620362073 .

22. Definition, diagnosis and classification of diabetes mellitus and its complications. Part 1: diagnosis and classification of diabetes mellitus provisional report of a WHO consultation. Diabet Med. 1998;15 (7):539-553. doi:10.1002/(SICI)1096-9136(199807)15:7<539::AIDDIA668>3.0.CO;2-S

23. Cleeman JI, Grundy SM, Becker D, Clark L. Expert panel on detection, evaluation and treatment of high blood cholesterol in adults: executive summary of the third report of the national cholesterol education program. JAMA. 2001;285:2486-2497. doi:10.1001/ jama.285.19.2486

24. The IDF consensus worldwide definition of the metabolic syndrome. Available from: http://www.idf.org/webdata/docs/IDF_Meta_def_ final.pdf. Accessed June 11, 2011.

25. Erasmus RT, Soita DJ, Hassan MS, et al. High prevalence of diabetes mellitus and metabolic syndrome in a South African coloured population: baseline data of a study in Bellville, Cape Town. S Afr Med J. 2012;102(11):841-844. doi:10.7196/SAMJ.5670

26. Peer N, Lombard C, Steyn K, Levitt N. High prevalence of metabolic syndrome in the Black population of cape town: the Cardiovascular Risk in Black South Africans (CABRISA) study. Eur J Prev Cardiol. 2014;1-7.

27. Ogbera A. Prevalence and gender distribution of the metabolic syndrome. Diabetol Metab Syndr. 2010;2:1-5. doi:10.1186/17585996-2-1

28. Kelliny C, William J, Riesen W, Paccaud F, Bovet P. Metabolic syndrome according to different definitions in a rapidly developing country of the African region. Cardiovasc Diabetol. 2008;7:27. doi:10.1186/1475-2840-7-27

29. Tran A, Gelaye B, Girma B, et al. Prevalence of metabolic syndrome among working adults in Ethiopia. Int J Hypertens. 2011;2011:8. doi: $10.4061 / 2011 / 193719$

30. Kaduka LU, Kombe Y, Kenya E, et al. Prevalence of metabolic syndrome among an urban population in Kenya. Diabetes Care. 2012;35(4):887-893. doi:10.2337/dc11-0537

31. Grundy SM. Metabolic syndrome pandemic. Arterioscler Thromb Vasc Biol. 2008;28:629-636. doi:10.1161/ATVBAHA.107.151092

32. Shaibu S, Holsten JE, Stettler N, et al. Adolescent obesity prevention in Botswana: beliefs and recommendations of school personnel. Int J Sch Nurs. 2012;28(3):220-229. doi:10.1177/1059840511429003

33. Third National Health and. Nutrition examination survey prevalence of the metabolic syndrome among US adults: findings from the third national health and nutrition examination survey. JAMA. 2002;287 (3):356-359. doi:10.1001/jama.287.3.356
34. Azizi F, Salehi P, Etemadi A, Zahedi-Asl S. Prevalence of metabolic syndrome in an urban population: Tehran Lipid and Glucose Study. Diabetes Res Clin Pract. 2003;61(1):29-37. doi:10.1016/S01688227(03)00066-4

35. Hwang L, Bai C, Chen C. Prevalence of obesity and metabolic syndrome in Taiwan. J Formos Med Assoc. 2006;105(8):626-635. doi:10.1016/S0929-6646(09)60161-3

36. Lobo RA. Metabolic syndrome after menopause and the role of hormones. Maturitas. 2008;60:10-18. doi:10.1016/j.maturitas. 2008.02.008

37. Jouyandeh Z, Nayebzadeh F, Qorbani M, et al. Metabolic syndrome and menopause. J Diabetes Metab Disord. 2013;12:1. doi:10.1186/ 2251-6581-12-1

38. Eshtiaghi R, Esteghamati A, Nakhjavani M. Menopause is an independent predictor of metabolic syndrome in Iranian women. Maturitas. 2010;65(3):262-266. doi:10.1016/j.maturitas.2009.11.004

39. Rosano GM, Vitale C, Marazzi G, Volterrani M. Menopause and cardiovascular disease: the evidence. Climacteric. 2007;10(Suppl 1):19-24. doi:10.1080/13697130601114917

40. Bowling M, Oparil S, Hage F, Hilgers R, Xing D. Chapter 1: sex hormones and vascular function. Sex Horm. 2012;1-31. doi:10.5772/ 1313

41. Lizcano F, Guzmán G. Estrogen deficiency and the origin of obesity during menopause. Biomed Res Int. 2014;757461. doi:10.1155/2014/ 757461

42. Grossmann M. Low testosterone in men with type 2 diabetes: significance and treatment. $J$ Clin Endocrinol Metab. 2011;96 (8):2341-2353. doi:10.1210/jc.2011-0118

43. Salam R, Kshetrimayum AS, Keisam R. Testosterone and metabolic syndrome: the link. Indian J Endocrinol Metab. 2012;16(Suppl 1): S12-S19. doi:10.4103/2230-8210.94248

44. Lindström J, Louheranta A, Mannelin M. The Finnish Diabetes Prevention Study (DPS): lifestyle intervention and 3-year results on diet and physical activity. Diabetes Care. 2003;26:3230-3236. doi: $10.2337 /$ diacare.26.12.3230

45. Tuomilehto J, Lindström J, Eriksson JG, et al. Prevention of type 2 diabetes mellitus by changes in lifestyle among subjects with impaired glucose tolerance. NEJM. 2001;344:1343-1350. doi:10.1056/NEJM200105033441801

46. Karmali KN, Lloyd-Jones DM. Adding a life-course perspective to cardiovascular-risk communication. Nat Rev Cardiol. 2013;10 (2):111-115. doi:10.1038/nrcardio.2012.185

\section{Publish your work in this journal}

Diabetes, Metabolic Syndrome and Obesity: Targets and Therapy is an international, peer-reviewed open-access journal committed to the rapid publication of the latest laboratory and clinical findings in the fields of diabetes, metabolic syndrome and obesity research. Original research, review, case reports, hypothesis formation, expert opinion and commentaries are all considered for publication. The manuscript management system is completely online and includes a very quick and fair peer-review system, which is all easy to use. Visit http://www.dovepress.com/testimonials.php to read real quotes from published authors. 